\title{
Literacy Research and Instruction
}

\section{Better Together: Combining Reading and Writing Instruction to Foster Informative Text Comprehension}

\section{Catherine Turcotte \& Pier-Olivier Caron}

To cite this article: Catherine Turcotte \& Pier-Olivier Caron (2020) Better Together: Combining Reading and Writing Instruction to Foster Informative Text Comprehension, Literacy Research and Instruction, 59:3, 240-259, DOI: 10.1080/19388071.2020.1752861

To link to this article: https://doi.org/10.1080/19388071.2020.1752861

\section{0.}

Submit your article to this journal 준

Цll Article views: 70

Q View related articles $\sqsubset$

View Crossmark data 


\title{
Better Together: Combining Reading and Writing Instruction to Foster Informative Text Comprehension
}

\author{
Catherine Turcotte (1) ${ }^{\mathrm{a}}$ and Pier-Olivier Caron $\mathbb{1}^{\mathrm{b}}$
}

aDépartement D'éducation Et Formation Spécialisées, Université Du Québec À Montréal, Montréal, Canada; 'Division Département Des Sciences Humaines, Lettres Et Communications, TELUQ - Université Du Québec, Quebec City, Canada

\begin{abstract}
This study conducted with French-speaking students living near Montréal, Canada, assess if teaching the shared knowledge between reading and writing of informative texts improves reading comprehension in fourth grade (9-10 years old) to a greater extent than teaching that separates reading and writing. Teachers participating in the experiment received teaching material and training during 1 year prior to data collection. The teaching approach involved three steps and included activities that were spread over 20 weeks and lasted approximately 2 $\mathrm{h}$ per week. Teachers from the non-experimental condition teach reading comprehension and writing strategies in a dissociated way. Students ( $n=248$ ) were tested with a reading comprehension assessment in September and May. Results show a significant interaction between time and groups, suggesting a moderate effect size. The experimental group started the experiment slightly behind in reading comprehension and ended up significantly better than the control group. Teaching how to articulate knowledge in reading and writing might favor reading comprehension of informative texts better than teaching strategies in a dissociated way. However, the introduction of such an approach required continuous training and robust teacher support.
\end{abstract}

\section{KEYWORDS}

Expository/informational text; teacher Education; comprehension; writing

In third and fourth grade, students are asked to read substantially more informative texts in class content (McNamara, Ozuru, \& Floyd, 2017). These texts may seem simple since they articulate organized information on a specific topic; however, they are rather complex since this information is often far removed from the reader's knowledge, and the organization of ideas is based on less familiar structures compared to narratives and stories (Dymock, 2005; Fayol, 2016; Williams \& Pao, 2013). Thus, nearly one-third of fourth graders have reading comprehension scores that are below the basic level, which suggests they experience difficulties with critical elements of comprehending informative texts, such as identifying main ideas or identify the authors' purpose (National Center for Education Statistics, 2015). In addition, instruction on informational text characteristics appears to occur rather infrequently in primary grade classrooms, which might be partially due to teachers' lack of knowledge of this text genre (Reutzel, Jones, Clark, \& Kumar, 2016). This is particularly alarming knowing that understanding these texts is considered a key competence in modern information society (Magnusson, Roe, \& Blikstad-Balas, 2018). In this sense, while informative texts seem challenging for students, they also seem difficult to teach. 
The complexity of informative texts has often been cited (see Best, Floyd, \& McNamara, 2008; Meyer \& Ray, 2011), as well as the usefulness of combining reading and writing instruction to promote better literacy skills (see Graham \& Hebert, 2010). This two-year project thus examines the effects of instruction promoting a combination of reading and writing informative texts on reading comprehension of fourth graders in a Frenchspeaking population. It answers the following question, "Does teaching based on the combination of reading and writing informative texts favor comprehension of these texts in Grade 4 students to a greater extent than teaching that separates reading and writing?"

The first year of this project was spent on preparing the teachers and developing activities, while the second year was dedicated to the experiment. This article first describes theoretical and scientific foundations of the study. The method section presents teachers training in the experimental condition, classroom interventions, as well as data collection. Then, descriptive analysis and a mixed ANOVA assess whether there are differences between the control and experimental groups and between the pre-and postinterventions. In the end, discussion deepens the scope of this study.

\section{Literature review and theoretical framework}

In order to inform the intervention carried out in this project, the following sections present the importance of the links between microstructure and macrostructure in reading comprehension based on Kintsch theoretical model (2013). Then, the importance of linking reading and writing activities is also described.

\section{Importance of the links between microstructure and macrostructure}

Informative texts organize information, ideas, and facts within structures that reflect cognitive processes essential to understanding and communicating effectively (Williams, 2005). Indeed, both readers and writers of informative texts must take information (content) into account while relying on a structure to organize it. However, this organization depends on many interwoven elements.

According to Kintsch (2013), readers must read and understand the words, grasp the meaning of the sentences and the links between them (microstructure), and be able to recognize the themes developed and how the ideas are organized (macrostructure). In this respect, text structures represent fundamental keys to understanding virtually any written discourse (Williams et al., 2014). Thus, expressing ideas effectively in writing requires appropriate word choice and good syntax, but it also involves local and global coherence, which requires an understanding of how propositions and sentences are structured into paragraphs and sections (Kim, Petscher, Wanzek, and Al Otaiba (2018).

Five structures are commonly found in informative texts according to Meyer's typology (1985). Descriptive structure relates ideas by elaboration of attributes, specifics, or setting information. Comparison structure presents ideas by differences and/or similarities. Sequence structure organizes ideas that must be understood within particular steps. Cause and effect structure relates ideas that cause an outcome or an effect. Problem and solution structure express a question or a problem and some answers or solutions (Meyer \& Ray, 2017; Reutzel et al., 2016). 
It is sometimes difficult to identify a single structure in a text since each paragraph may have an intention, a main idea, and therefore a structure that differs from the other paragraphs. A writer who wants to write a text about beavers may begin with a paragraph describing the characteristics of this animal, followed by a paragraph comparing it with raccoons, and ending with a paragraph having a cause-and-effect structure explaining how beaver dams favorably influence ecosystems. It is therefore important to learn how to use this knowledge of structures in many reading and writing contexts.

The relationships between text structure awareness/knowledge and reading comprehension are well established (Duke, Pearson, Strachan, \& Billman, 2011; Goldman \& Rakestraw, 2000; Meyer \& Ray, 2017). Students who have learned to recognize structures use them to understand how information in a text is organized and are more likely to retain important ideas from texts. This has been demonstrated in early elementary (Williams, 2005; Williams et al., 2014) and late elementary (Dymock, 2005) students, as well as students with difficulties (Hebert, Bohaty, Nelson, \& Brown, 2016). In writing, students who master structures produce more coherent and richer texts (Englert, Stewart, \& Hiebert, 1988; Graham, McKeown, Kiuhara, \& Harris, 2012; Kirkpatrick \& Klein, 2009; Meyer \& Ray, 2017).

However, appropriate use of structures tends not to arise intuitively. Indeed, it is rather a result of planned and direct instruction on structures, and awareness of the characteristics of informative texts, that students succeed in this regard (Pyle et al., 2017). Moreover, researchers have suggested analyzing representative texts of each structure in order to clarify this type of organization with students (see Dolz, Noverraz, \& Schneuly, 2001; Jolibert, 1988; Shanahan, 2014). To achieve this, teachers must find well-structured informational texts (Reutzel et al. (2016). Roehling, Hebert, Ron Nelson, and Bohaty (2017) also recommend introducing different text structures in close proximity in order to highlight their specific characteristics, which may help students discriminate and recognize structures while reading.

Understanding text structure also depends on local-level comprehension of a text, which refers to microstructure (Kintsch, 2013). Local-level comprehension is achieved by integrating the meanings of successive clauses and sentences (Cain, 2009). In this respect, signal words or markers in and between sentences are important clues that indicate relationships between ideas and ensure text consistency (Sáenz \& Fuchs, 2002; White, 2012). For example, the words "first," "next," and "finally" may indicate a sequence, and the words "less than" and "while" can indicate comparison. Students must nevertheless learn not to rely on these signal words without considering other clues in the text. The marker "so" is not only used to illustrate a fact; it can also be used to show the effects of a phenomenon. Readers and writers must, therefore, learn to master these indicators with nuance. A recent meta-analysis (Pyle et al., 2017) on the effectiveness of expository text structure instruction for improving comprehension revealed that signal word instruction was included in many high-quality studies. Researchers also recommend that these be taught between Grades 4 and 8 (Meyer, Wijekumar, \& Lei, 2018).

At the microstructure level, a text also contains anaphora, whose function is to maintain text coherence and develop information by recalling antecedents without always repeating them (Tavares, Fajardo, Avila, \& Salmeron, 2015). For example, instead of repeating the word "beaver," a text can use the pronoun "it" or another noun group such as "this rodent," "this mammal," or "this herbivore," since the overuse of pronouns 
reproduces the repetitive effect they are supposed to combat (Colognesi \& Deschepper, 2013). Problems using anaphora and maintaining the meaning of texts are often detected in students with reading difficulties (Cain, 2009). In French, especially, comprehension of anaphora is difficult since they rely notably on readers' knowledge of grammar and syntax, readers' grasp of a wide variety of pronouns and number/gender agreement, and their ability to identify noun groups.

In sum, readers must use the meaning of sentences and the links between them (Ecalle, Bouchafa, Potocki, \& Magnan, 2013), and then identify the structure of each paragraph to access the main idea, organization, and line of thought. The opposite is also true, because readers who adequately predict the structure of each paragraph will have a basis to understand the sentences and links that connect them. It is a back-and-forth process between text microstructure and macrostructure, each feeding comprehension of the other (Mesmer, Cunningham, \& Hiebert, 2012). Likewise, writers who, from the outset, determine and structure the most essential ideas of their text will be able to organize and articulate examples, secondary ideas, and details. Such knowledge, skills, and strategies regarding micro and macrostructure are therefore as important in reading as in writing. Indeed, researchers have recommended that teachers develop awareness among students that reading and writing are different activities but are based on a constellation of shared knowledge (Fitzgerald \& Shanahan, 2000; Williams \& Pao, 2013).

\section{Importance of the links between reading and writing}

While a number of studies on the relationship between reading and writing have shown that this interplay has not received the same degree of attention as the activity of reading and writing taken alone (Costa, Edwards, \& Hooper, 2016; Fitzgerald \& Shanahan, 2000; Parodi, 2007), other studies have recently contributed to documenting it more precisely (Graham \& Hebert, 2011; Hebert, Gillespie, \& Graham, 2013; Kim et al., 2018). Nonetheless, teaching shared knowledge in reading and writing is not self-evident. Historically, reading has been viewed as a receptive skill, while writing has been viewed as a productive skill (Fitzgerald \& Shanahan, 2000). This might explain why these links are under-researched and why there is not much guidance for teachers. In addition, one-way and two-way relationships between reading and writing skills on multiple language levels (words, sentences, texts) change over the course of a student's development (Abbott, Berninger, \& Fayol, 2010; Kim et al., 2018). As such, although teachers are aware of the importance of making connections between reading and writing, they find it difficult to do so without long-term support (Doubet \& Southall, 2018).

Recent studies have shown that reading and writing use shared knowledge and cognitive processes (Graham \& Hebert, 2011) but also intention, since authors write with the reader in mind and readers read with the author in mind (Fitzgerald, 2013). Students, however, are not necessarily aware of this interaction, and it is up to the teacher to make it concrete and explicit. Shanahan (2014) considers that one way to deepen students' reading and writing skills is to have them read model texts and then imitate some aspects of the model through their own writing. This interaction between reading and writing can scaffold students' disciplinary writing and give them the opportunity to position themselves as disciplinary writers (Håland, 2017). The study of model or mentor texts, therefore, benefits both students and teachers. It provides students with quality examples to inform their writing while presenting a variety of techniques in writing that support teaching (Pytash \& Morgan, 2014). 
In turn, interactions between writing and reading that favor reading development are also supported by Graham and Hebert (2011) in a meta-analysis. They recommend having students write about what they read (respond to a text, summarize, etc.), teaching skills and processes that go into creating text to improve comprehension (text structures, sentence construction, etc.), and increasing students' own writing activities. Hebert, Gillepsie, and Graham's (2013) meta-analysis of the impact of writing activities on reading comprehension shows that multiple writing activities can improve different aspects of reading comprehension. The authors suggest that rather than looking for one best writing activity, teachers or program developers should consider the level and aspects of comprehension they wish to enhance and select writing activities that develop the types of thinking corresponding to such comprehension.

This is also pointed out in a recent study by Kim et al. (2018), which showed that reading skills contribute to writing from Grades 3 to 6 , but that the opposite was much harder to demonstrate. Researchers concluded that writing acquisition may contribute to students' awareness of how information should be structured and, consequently, foster reading comprehension; however, this might "require instruction that explicitly identifies these aspects to promote the transfer of skills between writing and reading comprehension." This statement aptly reflects the objective of our study, whose main question is "Does teaching based on the combination of reading and writing informative texts favor comprehension of these texts in Grade 4 students to a greater extent than teaching that separates reading and writing?"

By creating such a teaching approach and analyzing its effects, this study has the potential to contribute to the advancement of knowledge in the field of teaching knowledge and strategies related to these texts. In light of Hebert et al.'s (2016) recommendation to conduct more research on the potential interactions between various instructional approaches, the present study is a step in that direction.

\section{Method}

This study aims to better understand if teaching based on the combination of reading and writing informative texts favor comprehension in Grade 4 students to a greater extent than teaching that separates reading and writing. This section describes participants, the preparation of teachers in year 1 and the experimentation in year 2 . It also presents teachers practices in the control group, as well as instrument and data collection.

\section{Participants}

Data presented in this article came from 248 students in Grade 4 (9-10 years old) participating in the second year of the project. From this sample, 184 were in the experimental group and 64 were in the control group. All attended French-language public schools located in middle-class neighborhoods near Montréal, Canada. There was approximately the same number of boys (51\%) as girls (49\%), and their average age was 9.8 years at the beginning of the study. This study also included 10 teachers, 7 in the experimental group and 3 in the control group. All had more than 10 years of teaching experience. Teachers in the experimental group received training for 1 year (Year 1 ) with a different cohort of students prior to the experiment and collection of data (Year 2). 


\section{Intervention}

The intervention was created by a research team - composed of a researcher, a graduate research assistant, and three educational advisors - that developed this approach from the literature discussed in the previous sections. The educational advisors in the study came from school boards. They were specialized teachers who visit classrooms regularly and offer continuing education training to help teachers with literacy instruction. The approach developed with them included three steps for teaching the five text structures (Meyer, 1985). Since many teachers do not feel equipped to deliver instruction in an integrated reading-writing fashion (Doubet \& Southall, 2018), it was decided to devote a year to preparation in order for them to develop a solid base of knowledge and to ensure long-term support prior to the data collection.

\section{Year 1: teacher support and training in the experimental group}

During this first year, five training days spread between September and March allowed the teachers to acquire the key concepts related to text structures, signal words, strategies for reading and writing informative texts, and linking these activities. They also learned how to coordinate the sequence of already crafted activities belonging to each step of the intervention (see next section). These activities were modeled by researchers and advisors, discussed and integrated into teachers' planning. In turn, teachers were also invited to practice these activities during training days to receive help and feedback. A ten-page document was provided to the teachers at each meeting so they would have a written record of the training and a timetable to implement the sequence of activities. As such, teachers received a good deal of theoretical and practical training, but they were also encouraged to incorporate, between meetings, activities from steps 1,2,3. The researchers and advisors also provided in-class support to all the teachers in the form of a two-hour visit after each of the five training days. This support consisted in co-teaching an activity, giving feedback on the teacher's practice and readjusting knowledge of concepts that were forgotten or misrepresented with the teacher. During the training, the teachers also shared their experiences with the experimental activities. This allowed review and improvement of the activities to better meet the needs of both students and teachers.

In the second year, teachers not only had good theoretical knowledge of the concepts involved but had also experimented with the new practices. Thus, in Year 2, teachers were ready to experiment with a more systematic teaching approach and follow a precise timetable between the end of September and the beginning of April. They were above all able to understand the value of this approach and the framework underlying it. In an additional five days of training, each day containing a five-hour session, they received more material as the team identified new model texts, instructions to improve their knowledge of structures, small group tutoring to remember each activity, and a teaching schedule to carry out the activities.

\section{Year 2: intervention}

The teaching approach involved three steps. It included activities that were spread over 20 weeks and lasted approximately $2 \mathrm{~h}$ per week, between the end of September and the end of March. Teachers were asked to integrate these $2 \mathrm{~h}$ in their regular literacy teaching that demands an average of five to $6 \mathrm{~h}$ a week. Table 1 presents a summary of each step of the approach. 
Table 1. Steps of year 2 intervention.

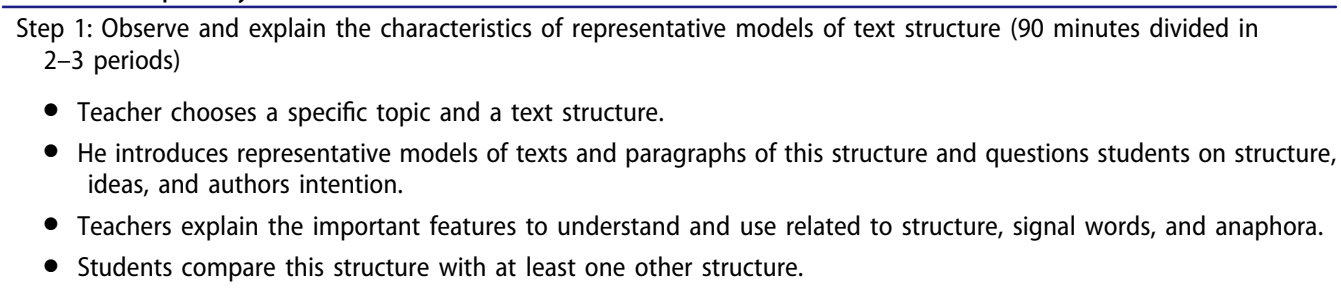

Step 2: Harness the knowledge developed in Step 1 and facilitate the back and forth between reading and writing (about 3 hours spread over a few days)

- Students classify paragraphs according to the structure.

- They look for representative sentences and paragraphs in documentary books and clarify their knowledge on targeted structure.

- They make sentence combinations with appropriate markers and anaphora.

- They transform paragraphs (descriptive paragraphs become comparative, for example).

- They finished incomplete paragraphs according to the targeted structure.

- They write a whole paragraph and share with other students for feedback on structure, signal words, and anaphora.

- Each activity ends with a large group discussion on the aspects of microstructure and macrostructure to retain.

Step 3: Record knowledge (1 hour)

- Teacher asks the students to write a short definition of the structure.

- Students also draw a graphic organizer of it, cut and paste a paragraph that contains this structure, and then add a bank of markers related to the structure that are useful for reading or writing.

- Teacher uses these records as soon as a structure is encountered in a text, regardless of the discipline.

Step 1 of this approach was to observe and explain the characteristics of "representative" models of text structure. This step lasted about 90 min divided into two or three class periods. The idea of text modeling is to get students to carefully and analytically read texts to identify the key features to be reproduced. According to Shanahan (2014), students need to engage in such activities with awareness in order to understand specific features of text craft and structure. At this stage, teachers presented between five and six texts and model paragraphs (suggested by the research team) with the desired characteristics. For example, a model paragraph with a comparative structure deals with two objects and uses appropriate relationship markers (e.g., whereas, while, more than) to show what distinguishes them. Authors of such paragraphs use anaphora in order for the readers to reactivate the right antecedent word. Teachers questioned the students on their observations and then explained the important features to understand and use related to structure, signal words, and anaphora. They compared this paragraph with model descriptive paragraphs and recorded differences between each structure. This allowed students to highlight each structure characteristics in order to discriminate them (Roehling et al., 2017). All reading activities were created around specific topics, for example the Saint Lawrence River, in order to build background knowledge that can be invested in writing activities.

Step 2 lasts about $3 \mathrm{~h}$ and was spread over a few days. It immersed the students in a variety of activities to harness the knowledge developed in Step 1 and to facilitate the back-and-forth between reading and writing while maintaining focus on one chosen topic. 
Activities ranged from simple to more complex in order for students to progressively mobilize their knowledge and skills in more demanding tasks. Students were asked to classify paragraphs about the Saint Lawrence River according to their structure (comparative or descriptive) and then, to look for comparative sentences and paragraphs in documentary books about rivers. After they succeeded in these tasks and again clarified each structure and its characteristics, they made sentence combinations with appropriate markers and anaphora. The next activity consisted in turning descriptive paragraphs into comparative paragraphs. When all these activities were well accomplished, they finished incomplete paragraphs according to a structure, and wrote a whole paragraph with specific structures. These paragraphs were then read by other students, who gave feedback on structure, signal words, and anaphora. Students could work alone or in teams of two or four. Each activity ended with a large group discussion on the aspects of microstructure and macrostructure to retain. Appendix A shows samples of step 1 and step 2 activities.

Step 3 was to document this knowledge in the form of a record as part of a repertoire for the students. It lasted about $1 \mathrm{~h}$. At this stage, the teacher asked the students to write a short definition of the structure, draw a graphic organizer of it, cut and paste a paragraph about the Saint Lawrence River that contains this structure, and then add a bank of markers related to the structure that are useful for reading or writing. Teachers were encouraged to use these records as soon as a structure was encountered in a text, regardless of the discipline.

\section{Fidelity of implementation}

A concern of the study was the extent to which the interventions were being implemented as intended by the research team. When implementation occurs in a natural setting, variations are expected (O'Donnell, 2008). During the first year of the project, some activities were modified to best meet classroom needs. As such, during the second year, teachers were expected to implement the critical features of the program. To better achieve this goal, activities were supported by planning charts, in-class PowerPoint presentations, texts, and ready-made procedures. Also, during Year 2, a member of the research team visited the experimental classrooms monthly to document implementation.

During this monthly visit, a research team member took notes on the progress of activities through non-participant observation. They noted whether the activity was the one planned, whether it was conducted from beginning to end, and whether the material devoted to the activity was used in a consistent manner. These three items received a score of 0 (corresponding slightly or not at all to what was expected) or 1 (corresponding to what was expected). Although the teachers were observed only once a month, the observations were revealing. In school settings, especially when young students are involved, a high degree of adherence is considered possible only when the program has been correctly implemented on a regular basis and for a significant period of time, that is, when the intervention has become a well-rehearsed routine (Vuattoux, Japel, Dion, \& Dupéré, 2014). Adherence percentage was calculated by dividing the total number of items receiving " 1 " from the observer by the total number of items, and then multiplying by 100 . Adherence was found to be $94 \%$.

\section{Teachers in the control group}

In the second year of the project, three teachers who had not yet participated in the study were chosen to be in the control group. They were nominated by school boards because they 
teach reading and writing strategies with teaching materials consistent with the provincial curriculum, and because they had received training by their school board in the past 3 years on the explicit teaching of reading and writing strategies. They also each had more than 10 years' experience teaching Grade 4. A review of these teachers' monthly teaching plans was conducted, as well as an oral interview. Their teaching plans included three columns devoted to a) time spent on teaching every reading and writing activities, b) reading or writing strategies taught and c) teaching approached (explicit, modeling, guiding, etc.).

During the oral interview, they reported having implemented the following practices:

1 - They devoted an average of $6 \mathrm{~h}$ per week to activities focusing on reading and writing. Reading strategies taught included predicting, activating knowledge, inferring, and using story grammar and text structure. Strategies related to planning, generating, and organizing ideas, and revising and editing had to be part of the writing instruction. These strategies were consistent with those proposed in the training they received from their school board and with those from the provincial curriculum.

2 - All these strategies were taught by explaining the strategy, modeling, and guiding student practice. The strategies were introduced one by one using the material (texts and activity records) provided during training.

3 - Reading and writing were taught separately, i.e., some teaching activities were related to reading while others were related to writing. Classroom schedules during the week (Monday to Friday) included specific reading and writing periods. The training provided to the control group teachers by the school board did not consist of linking reading and writing but taught strategies specific to each activity.

Data from the interviews corresponded to the data from monthly planning. Hence, the hours spent on activities focused on reading and writing, the strategies taught and the teaching approach revealed in the interviews were consistent with the planning. In sum, in light of the criteria guiding the selection of teachers by the school board, their teaching material and planning, and their responses from the initial survey, the teachers devoted many hours to reading and writing and to teaching reading and writing strategies. Nevertheless, it is unlikely that the teachers provided a unified teaching approach to reading and writing.

\section{Instrument}

The reading comprehension test was group-administered and demanded short written responses. It required students to read an entire text about "tornadoes" and answer openended questions about literal, inferential, and textual macrostructure. The text is 575 words long and had readability corresponding to Grade 4, as analyzed with the software LISI in French (Mesnager, 2002). Each item has a 0 or 1 score. A scoring grid was created to guide correctors and give examples of correct and incorrect answers.

The test was inspired by reading comprehension models developed by Irwin (2007) and by Kintsch (2013). As such, it includes macrostructure (text structures and main ideas) and microstructure items (sentences and relationship between sentences). Regarding macrostructure comprehension, two items ask students to identify the main ideas in different paragraphs and one item asks them to reorganize text structure with a graphic organizer. In addition, items 6 and 7 asked students to explain causes and effects in paragraphs having this particular structure. The test is very similar to tests that students encounter during the school year and it aims to present 
strong psychometrical and theoretical standards to identify students' strengths and weaknesses in different comprehension processes (O’Reilly, Sabatini, Bruce, Pillarisetti, \& McCormick, 2012).

The test had previously been developed and validated with 216 French-Canadian students in 2015, using the Rasch model (1980/1960) to identify each item's level of complexity and to assess the probability of readers of different abilities correctly answering the items. The internal consistency of the test was determined with a Cronbach's alpha of 0.72. The item characteristic curves and test information function showed that overall, the test was useful in assessing students with average skills, but more specifically useful for assessing those with skill levels between -1 and 1 . Appendix B shows samples of the test and samples of correct and incorrect answers.

\section{Data collection and procedure}

The study complied with all regulations regarding research involving human participants, as required by the university ethics committee and the participating school boards. On Year 2 of the study, all students completed the reading comprehension test in September and May, taking between 45 and $55 \mathrm{~min}$ to do so. The tests were scored by research assistants. One of the assistants had a master's degree in special education. The other two assistants were graduating students in special education. A rate of $30 \%$ of the tests underwent an interjudge agreement procedure first amounting to $96 \%$. The scorers reconciled all divergences by reviewing and discussing each discrepancy. This procedure gave scorers the opportunity to discuss items and answers that were harder to score, clarify concepts and come to an agreement. For all tests, where there was a disagreement between scorers, they would discuss the issue until they came to a unanimous final decision.

\section{Results}

The results followed four steps. First, we carried out a preliminary cleaning of the data. Second, we described the success rate for each item of the comprehension test. Third, we carried out a factor analysis based on the latent intercept of READING to better answer the research question, and created a READING comprehension factor (dependent variable) using a latent growth model. Finally, we carried out a mixed ANOVA to assess whether there were differences between the control and experimental group and between the pre- and post-interventions.

Preliminary inspection of the data showed that there was no significant missing data (less than $0.02 \%$ ). As item distributions were dichotomous (succeed/fail), there was no issue of skewness or kurtosis. Outlier detection was carried out and no outliers were found. All parametric assumptions were met.

Table 2 presents success rates for each item of the comprehension test at pre- and posttest. Both groups show progress in all items. During pretest, 10 out of 11 items were assessed at higher rates for students from the control group. The most notable differences are items 7, 8a, 8b, and 9, which assessed different processes (inferences and structure). During posttest, the results are reversed: the experimental group is more successful on 7 items, and the differences for the remaining items are less than 3\%. Anaphor, cause-effect, and text structure items are notably more successful for the experimental group at posttest. 
Table 2. Success rate (\%) for each item of the comprehension assessment at pre- and posttest for the experimental group (Exp.) and control group (Ctrl.).

\begin{tabular}{lccccc}
\hline & \multicolumn{2}{c}{ Pretest (\%) } & & \multicolumn{2}{c}{ Postest (\%) } \\
\cline { 2 - 3 } \cline { 5 - 5 } Item & $\begin{array}{c}\text { Exp. } \\
(n=184)\end{array}$ & $\begin{array}{c}\text { Ctrl. } \\
(n=64)\end{array}$ & & $\begin{array}{c}\text { Exp. } \\
(n=184)\end{array}$ & $(n=64)$ \\
\hline 1 - Literal information & 78 & 89 & 90 & 91 \\
2 - Literal information & 69 & 73 & 84 & 83 \\
3 - Main idea & 11 & 18 & 42 & 34 \\
4 - Main idea & 9 & 17 & 24 & 26 \\
5a - Anaphor (easy pronoun) & 40 & 62 & 56 & 44 \\
5b - Anaphor (complex pronoun) & 61 & 56 & 71 & 76 \\
6 - Cause-effect relationship & 61 & 57 & 60 & 59 \\
7 - Cause-effect relationship & 46 & 42 & 46 & 57 \\
8a - Lexical inference (morpheme clue) & 27 & 30 & 41 & 47 \\
8b - Lexical inference (context clue) & 16 & 40 & 56 & 44 \\
9 - Text structure (graphic organizer) & 18 & & & 45 \\
\hline
\end{tabular}

A factor analysis was carried out using Mplus (Caron, 2018; Muthén \& Muthén, 19982017) to generate a latent READING comprehension factor, which will be used as the dependent variable in the next analysis. As all items were related to reading comprehension, such a factor will better correspond to the construct of interest, as well as being more convenient to analyze and also more appropriate than other combining methods (such as summing all items). This was also necessary to obtain continuous variables for the mixed ANOVA. The factor loadings were extracted from the intercepts of a latent growth model to account for within-subject variances from the pre- and post-intervention measures. Figure 1 illustrates the analysis. Several intercepts were derived from the items. From these intercepts, the factor analysis extracted the relevant loading to generate the READING factor. It is worth noting that many other techniques were considered (averaging pre- and post-measures, constraining loadings, and measurement invariance, among others), which all led to the same factorial structure (and the same results in the mixed ANOVA). This procedure ensures more reliable and valid results by using all the information gathered. After a first run, the third item was dropped, because it was not significantly related to the factor. The latent factor explained $50.4 \%$ of the 10 remaining items. Figure 1 shows that all items had good to excellent loadings on the factor (from.480 to .896). These results show that the factor was adequate to describe READING. A factor for pre- and postintervention was saved in subsequent analyses.

A mixed ANOVA was then carried out in SPSS to assess whether there were differences between the control and experimental groups (between-subjects factor) and between the pre-and post-interventions (within-subjects factor) on READING. The results show a significant interaction between time and groups, $F(1,232)=38.139, p<.001, \eta_{\text {partial }}^{2}=$ 0.141. This is considered a moderate effect size. Figure 2 shows that the experimental group started the study slightly behind in READING (from the main effect post-hoc analysis, there is a significant difference, $p=.002$ ) and finished significantly ahead of the control group $(p=.036)$. In other words, the intervention increased READING abilities considerably compared to normal instruction and in such a way that the students were significantly better than the control group. Indeed, Table 2 shows that participants in the experimental group nearly doubled (1.94) their scores in reading comprehension, whereas the control group was 1.23 times better on average. 


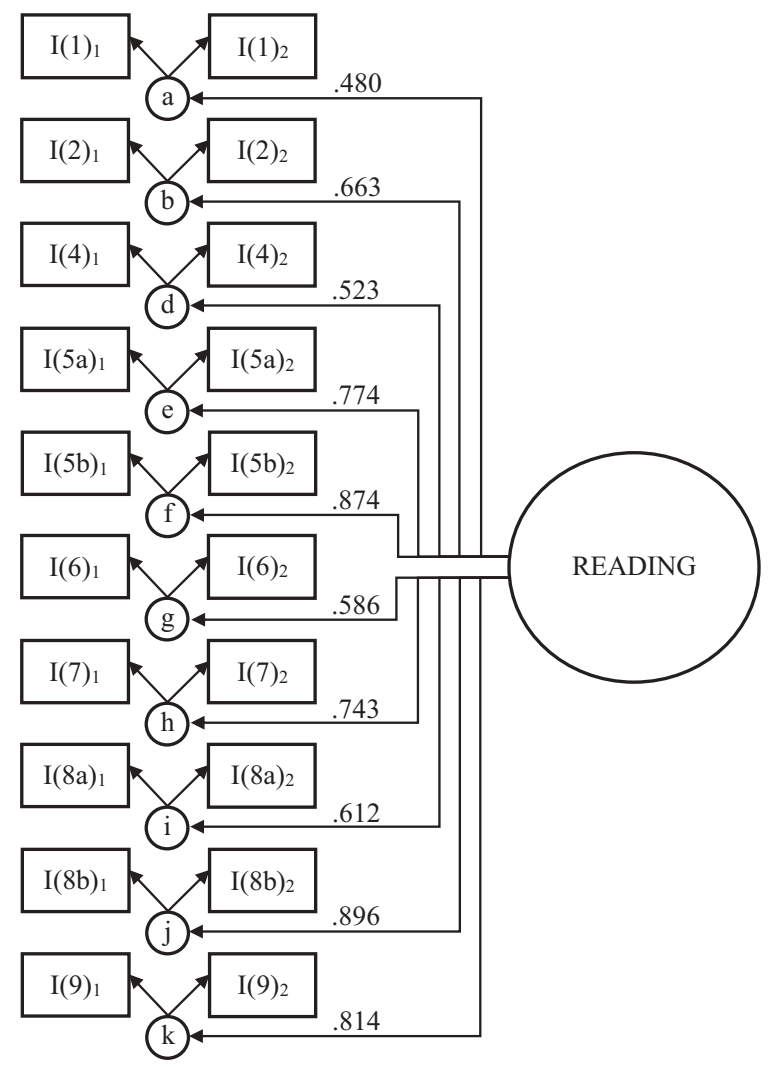

Figure 1. Factor analysis of the latent initial status of students regarding READING. This figure is an illustration of the structural equation modeling used herein. The letter I and the number in parentheses designates the item. The indices at the end distinguish between the pre (1) and post (2) interventions. The lowercase letters indicate the intercept in the latent growth models from which the factor READING was then extracted. The numbers are the loading of each latent intercept on the latent factor.

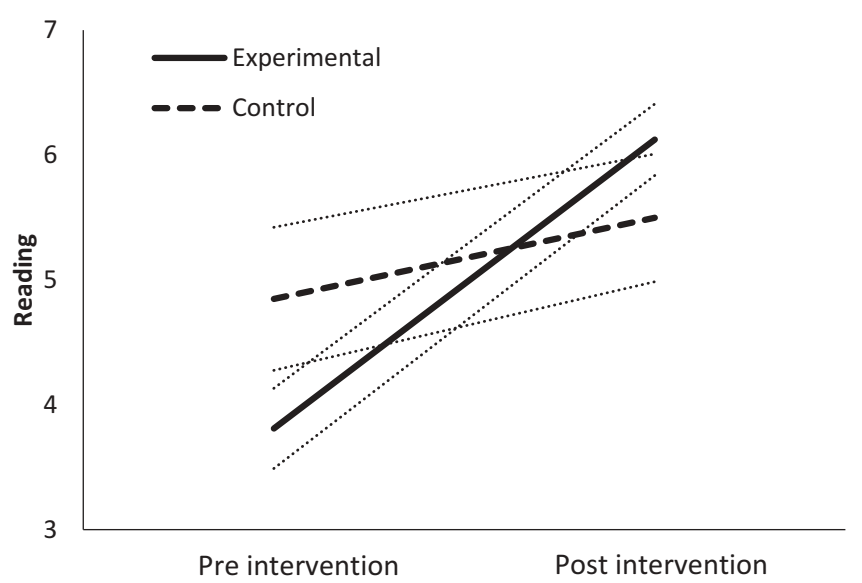

Figure 2. Comparison of the experimental and control instruction. The dashed line depicts the control group, and the solid line depicts the experimental group. The dotted lines represent the $95 \%$ confidence interval of the interaction effect for each group. The results show a significant interaction effect, in which the experimental group started the study with more negative results compared to the control group, and finished more positively. 


\section{Discussion}

This study intends to answer the following question: "Does teaching based on the combination of reading and writing informative texts favor comprehension of these texts in Grade 4 students to a greater extent than teaching that separates reading and writing?" In order to do so, a sequence of activities was created that focused on text structures, signal words, and anaphora while linking the reading and writing of informative texts. Our study aimed to contribute to the area of the reading-writing connection and to comprehension studies, more specifically regarding informative texts. As Hebert et al. (2016) recommended, there is a need to conduct more research to understand the nuances of potential interactions between various instructional reading-writing approaches.

In the first year of project implementation, the teachers in the experimental group were trained and followed in class; in the second year, they conducted a more formal activity sequence while continuing to receive in-class support and during the outside-school training days. During the second year, data were collected. Students' progress in reading comprehension was compared with that of students from other classes. In these classes, teachers followed regular teaching practices aimed at reading and writing strategies and knowledge, but separately rather than linked. Some positive effects of the reading-writing connection on reading comprehension of the Grade 4 students participating in the experiment were documented. By comparing the progress of students in these classes with that of students receiving more typical teaching strategies, that is, without particular attention to the link between reading and writing, this study contributes to a better understanding of how students can benefit from awareness and shared knowledge between reading and writing.

\section{Overview of findings}

Student progress in reading comprehension was more significant in the experimental group. Indeed, the results of these students were slightly less positive at the beginning of the year but generally more positive at the end of the year. For each of the comprehension questions during the test at the end of the year, the students who received the intervention showed a performance equal to or greater than that of students who were not exposed to the study's reading-writing approach. A closer look at the mixed ANOVA analysis, which considered an overall score, showed that the intervention increased the reading comprehension skills of the experimental group significantly more than the control group at the end of the study. In the posttest, students from the experiment wrote more complete and accurate answers than students from the control group when answering comprehension questions having different levels of complexity (literal, inferences, macrostructure). More importantly, they were more competent in identifying main ideas and expressing it in a sentence, understanding cause-effect relationships even when implicit and consigning important ideas in a graphic organizer based on text structure. These skills were precisely targeted in the instruction developed in this project.

By showing that the students from the experimental group have greater skills in the comprehension of an informative text than those from the control condition, this research reaffirms the importance of enriching existing practices in teaching reading and writing informative texts in order to develop better awareness and knowledge of text characteristics and useful strategies specific to this text genre. This reinforces the idea that adequate reading 
comprehension instruction involves identifying educationally relevant reading comprehension activities and directly addressing the component skills/knowledge bases involved in these activities (Catts \& Kamhi, 2017). By creating articulated reading and writing tasks on a same topic and inside a sequence, awareness of shared knowledge and skills between reading and writing might develop better, as students learn how to mobilize them more consciously.

Previous studies have shown that teaching text structures and signal words fosters comprehension among students from different school levels (see Pyle et al., 2017). Hence, integrating teaching of microstructure comprehension (in and between sentences) and macrostructure comprehension (text structures) is recommended. From a theoretical point of view, this also recalls Kintsch's (2013) model, inside which these two levels of comprehension are not isolated but interrelated. Better comprehension of macrostructure might also favor a better awareness of implicit information and therefore, help with inference making. As seen in the results, students from the experimental condition had better improvement in understanding anaphora between pre- and posttest than students from the control condition.

Other studies have also indicated that writing activities have effects on reading comprehension (Graham and Hebert, 2011). However, teaching writing and reading together in such an articulated fashion is not self-evident for teachers (Doubet \& Southall, 2018). Interestingly, Kim et al. (2018) suggest that such instruction should explicitly identify aspects that promote the transfer of skills between writing and reading comprehension. By focusing on text structures, signal words and anaphora in a back-and-forth sequence of reading and writing activities, the present study went a step further by combining these recommendations and potentially fostering reading comprehension of informative texts.

The results of this study, therefore, contribute to the existing scientific literature, highlighting that writing skills can foster reading comprehension, but also that teachers and program developers should consider the levels and aspects of comprehension they wish to enhance, and "select writing activities that develop the types of thinking corresponding to them" (Hebert et al., 2013). This study also contributes to the knowledge that having students read model texts and then imitate some aspects of the models through their own writing is beneficial (Shanahan, 2014). Furthermore, reinvesting these aspects into all reading activities afterward might further consolidate their skills and knowledge. Different stages of reinvestment might be necessary for some students to mobilize their knowledge in different tasks. Still, much more studies are needed to better understand how teachers can achieve this combination of reading and writing with greater regularity in their daily teaching practice, and how students improve their awareness of shared knowledge between various literacy activities.

\section{Implications for practice and teachers development}

Teachers could reinvest the result of this study by selecting specific aspects of reading comprehension (anaphora, markers, structures, main ideas, etc.) and create sequences that integrate reading and writing tasks. Activities in this study were sometimes quite concise, as they focused on precise objects and leaded to more elaborated tasks. Literacy teacher educators could also train future and in-service teachers to plan literacy activities with a reading and writing mindset by developing awareness of the shared knowledge between both activities. When possible, teachers mentoring and support inside classrooms by an expert could also represent a good way to encourage teachers to combine reading and writing. 


\section{Limitations and future research}

Introducing a new approach linking the reading and writing of informative texts is demanding and requires support. In a review of professional training, Wei, DarlingHammond, Andree, Richardson, and Orphanos (2009) reported that "Studies find strong effects of professional development on practice when it focuses on enhancing teachers' knowledge of how to engage in specific pedagogical skills and how to teach specific kinds of content." We doubt that our study would have promoted such teaching and awareness of the shared knowledge between reading and writing, if continuous training and robust teacher support had not been provided. The financial and human resources invested in this study in this regard were therefore significant. Another contribution of this study may well be about teachers training and their knowledge development on informative text. Qualitative data on these aspects will be explored in future articles.

The results of this study should be interpreted with caution. Even though the teachers in the control group did not report conducting activities that linked reading and writing, they may have done so without being fully aware. Furthermore, the comprehension test included only 11 items, which offered a limited view of the students' skills. No instrument can thoroughly evaluate comprehension, so the latter test was chosen for its strong theoretical support and its psychometric qualities. Further studies might use more instruments or combine data from both tests and students interviews in order to form a clearer idea of the contributions of such an approach. Further studies might also focus on the effects of using specific topics for articulated reading and writing activities. We did not assess the potential benefits of using specific topics, but further studies could potentially provide new data on the importance of background knowledge for such a sequence of activities.

Lastly, the teachers in the experimental group also taught several other notions related to oral and written language. The present study's activities do not represent the sum of classroom learning experiences. Spelling, syntax, narrative texts, and grammar were certainly taught and may have had an impact on student results. Similarly, in all school subjects (e.g., science, history), students were in contact with other informative texts and other tasks that may have also contributed to learning.

Written comprehension is multidimensional, informative texts are complex and dense, and awareness of the knowledge and strategies that can be useful in both reading and writing is not usually intuitive. This interplay of complex concepts does not simplify the support and continuing education training needs of the teachers asked to experiment these new approaches. Moreover, readers are no longer expected to only be good at understanding - they are also expected to become independent learners and creators of new knowledge. Therefore, to properly understand and use various text clues such as anaphora, markers, structures, and main ideas in reading and writing, these notions must be specifically taught in any community focused on learning.

\section{Disclosure statement}

No potential conflict of interest was reported by the authors. 


\section{Funding}

This work was supported by the Fonds de recherche du Québec - Société et culture (FRQSC) [2017LC-196854.].

\section{ORCID}

Catherine Turcotte (iD) http://orcid.org/0000-0001-9936-8013

Pier-Olivier Caron (10) http://orcid.org/0000-0001-6346-5583

\section{References}

Abbott, R. D., Berninger, V., \& Fayol, M. (2010). Longitudinal relationships of levels of language in writing and between writing and reading in grades 1 to 7. Journal of Educational Psychology, 102 (2), 281-298. doi:10.1037/a0019318

Best, R. M., Floyd, R. G., \& McNamara, D. S. (2008). Differential competencies contributing to children's comprehension of narrative and expository texts. Reading Psychology, 29(2), 137-164. doi:10.1080/02702710801963951

Cain, K. (2009). Children's reading comprehension difficulties: A consideration of the precursors and consequences. In C. Wood \& V. Connelly (Eds.), Contemporary perspectives on reading and spelling (pp. 59-75). New York, NY: Taylor \& Francis Books.

Caron, P.-O. (2018). La modélisation par équations structurelles avec Mplus. Québec: Presses de l'Université du Québec. ISBN 978-2-7605-4972-2.

Catts, H. W., \& Kamhi, A. G. (2017). Prologue: Reading comprehension is not a single ability. Language, Speech, and Hearing Services in Schools, 48(2), 73-76. doi:10.1044/2017_LSHSS-160033

Colognesi, S., \& Deschepper, C. (2013). La leçon de grammaire à l'intérieur du processus d'écriture: Le cas des anaphores et des procédés de reprises. In O.Bertrand \&I. Schaffner (Eds.), Enseigner la grammaire, 95-109. Paris,France: Les Éditions de l'École polytechnique.

Costa, L. C., Edwards, C. N., \& Hooper, S. R. (2016). Writing disabilities and reading disabilities in elementary school students. Learning Disability Quarterly, 39(1), 17-30. doi:10.1177/ 0731948714565461

Dolz, J., Noverraz, M., \& Schneuly, B. (2001). Séquences didactiques pour l'oral et pour l'écrit (Vol. IV). Bruxelles, Belgium: de Boeck \& Larcier.

Doubet, K. J., \& Southall, G. D. (2018). "Nobody but a reader ever became a writer": Integrating reading and writing instruction to help adolescents tell their stories. Virginia English Journal, 67 (2), 25-33.

Duke, N. K., Pearson, P. D., Strachan, S. L., \& Billman, A. K. (2011). Essential elements of fostering and teaching reading comprehension. What Research Has to Say about Reading Instruction, 4, 286-314.

Dymock, S. (2005). Teaching expository text structure awareness. The Reading Teacher, 59(2), 177-181. doi:10.1598/RT.59.2.7

Ecalle, J., Bouchafa, H., Potocki, A., \& Magnan, A. (2013). Comprehension of written sentences as a core component of children's reading comprehension. Journal of Research in Reading, 36(2), 117-131. doi:10.1111/j.1467-9817.2011.01491.x

Englert, C. S., Stewart, S. R., \& Hiebert, E. H. (1988). Young Writers' use of text structure in expository text generation. Journal of Educational Psychology, 80(2), 143-151. doi:10.1037/00220663.80.2.143

Fayol, M. (2016). De la lecture à la production verbale écrite, et réciproquement. Paper presented at the Symposium international sur la litéracie à l'école/International Symposium for Educational Literacy (SILE/ISEL) (2015: Jouvence, Québec, Canada) (pp. 103-119). Sherbrooke, Les Éditions de l'Université de Sherbrooke (ÉDUS). 
Fitzgerald, J. (2013). Constructing instruction for struggling writers: What and how. Annals of Dyslexia, 63(1), 80-95. doi:10.1007/s11881-011-0063-z

Fitzgerald, J., \& Shanahan, T. (2000). Reading and writing relations and their development. Educational Psychologist, 35(1), 39-50. doi:10.1207/S15326985EP3501_5

Goldman, S. R., \& Rakestraw, J. A., Jr. (2000). Structural aspects of constructing meaning from text. In M. L. Kamil, P. B. Mosenthal, P. D. Pearson, \& R. Barr (Eds.), Handbook of reading research (Vol. 3, pp. 545-561). Mahwah, NJ: Lawrence Erlbaum

Graham, S, \& Hebert, M. (2011). Writing to read: a meta-analysis of the impact of writing and writing instruction on reading. Harvard Educational Review, 81(4), 710-744. doi:10.17763/ haer.81.4.t2k0m13756113566

Graham, S., \& Hebert, M. A. (2010). Writing to read: Evidence for how writing can improve reading. A Carnegie Corporation Time to Act Report. Washington, DC: Alliance for Excellent Education.

Graham, S., McKeown, D., Kiuhara, S., \& Harris, K. R. (2012). A meta-analysis of writing instruction for students in the elementary grades. Journal of Educational Psychology, 104(4), 879-896. doi:10.1037/a0029185

Håland, A. (2017). Disciplinary literacy in elementary school: How a struggling student positions herself as a writer. The Reading Teacher, 70(4), 457-468. doi:10.1002/trtr.1541

Hebert, M., Bohaty, J. J., Nelson, J. R., \& Brown, J. (2016). The effects of text structure instruction on expository reading comprehension: A meta-analysis. Journal of Educational Psychology, 108 (5), 609-629. doi:10.1037/edu0000082

Hebert, M., Gillespie, A., \& Graham, S. (2013). Comparing effects of different writing activities on reading comprehension: A meta-analysis. Reading and Writing, 26(1), 111-138. doi:10.1007/ s11145-012-9386-3

Irwin, J. W. (2007). Teaching reading comprehension processes (3rd ed. Boston, MA: Pearson Allyn and Bacon.

Jolibert, J. (1988). Former des enfants producteurs de textes. Paris, France: Hachette Écoles.

Kim, Y. S. G., Petscher, Y., Wanzek, J., \& Al Otaiba, S. (2018). Relations between reading and writing: A longitudinal examination from grades 3 to 6. Reading and Writing, 31(7), 1591-1618. doi:10.1007/s11145-018-9855-4

Kintsch, W. (2013). Revisiting the construction-integration model of text comprehension and its implications for instruction. In D. E. Alvermann, N. J. Unrau, \& R. B. Ruddell (Eds.), Theoretical models and processes of reading (6th ed., pp. 807-839). Newark,DE: International Reading Association.

Kirkpatrick, L. C., \& Klein, P. D. (2009). Planning text structure as a way to improve students' writing from sources in the compare-contrast genre. Learning and Instruction, 19(4), 309-321. doi:10.1016/j.learninstruc.2008.06.001

Magnusson, C. G., Roe, A., \& Blikstad-Balas, M. (2018). To what extent and how are reading comprehension strategies part of language arts instruction? A study of lower secondary classrooms. Reading Research Quarterly, 54(2), 187-212. doi:10.1002/rrq.231

Mahwah, N. J., ErlbaumGraham, S., \& Hebert, M. (2011). Writing to read: A meta-analysis of the impact of writing and writing instruction on reading. Harvard Educational Review, 81(4), 710-744. doi:10.17763/haer.81.4.t2k0m13756113566

McNamara, D. S., Ozuru, Y., \& Floyd, R. G. (2017). Comprehension challenges in the fourth grade: The roles of text cohesion, text genre, and readers' prior knowledge. International Electronic Journal of Elementary Education, 4(1), 229-257.

Mesmer, H. A., Cunningham, J. W., \& Hiebert, E. H. (2012). Toward a theoretical model of text complexity for the early grades: Learning from the past, anticipating the future. Reading Research Quarterly, 47(3), 235-258. doi:10.1002/rrq.019

Mesnager, J. (2002). Pour une étude de la difficulté des textes, ou la lisibilité revisitée. Le Français aujourd'hui, 137(2), 29-42. doi:10.3917/lfa.137.0029

Meyer, B. J., \& Ray, M. N. (2011). Structure strategy interventions: Increasing reading comprehension of expository text. International Electronic Journal of Elementary Education, 4(1), $127-152$. 
Meyer, B. J., \& Ray, M. N. (2017). Structure strategy interventions: Increasing reading comprehension of expository text. International Electronic Journal of Elementary Education, 4(1), 127-152. Dallas, TX.

Meyer, B. J. F. (1985). Prose analysis: Purposes, procedures, and problems. In B. K. Britton \& J. Black (Eds.), Understanding expository text: A theoretical and practical handbook for analyzing explanatory text (pp. 269-304). Hillsdale, NJ: Erlbaum.

Meyer, B. J. F., Wijekumar, K., \& Lei, P. (2018). Comparative signaling words generated for expository texts by 4 th -8 th graders: Variations by text structure strategy instruction, comprehension skill, and signal word. Reading and Writing: An Interdisciplinary Journal, 31(9 - Special Issue: Text Structure in Reading and Writing), 1937-1968. doi:10.1007/s11145-018-9871-4

Muthén, L. K., \& Muthén, B. O. (1998-2007). Mplus user's guide (6th ed.). Los Angeles, CA: Muthén \& Muthén.

National Center for Education Statistics. (2015). NAEP 2015 reading: A report card for the nation and the states. Washington, DC: U. S. Department of Education, Institute of Education Sciences.

O’Donnell, C. L. (2008). Defining, conceptualizing, and measuring fidelity of implementation and its relationship to outcomes in K-12 curriculum intervention research. Review of Educational Research, 78(1), 33-84. doi:10.3102/0034654307313793

O'Reilly, T., Sabatini, J., Bruce, K., Pillarisetti, S., \& McCormick, C. (2012). Middle school reading assessment: Measuring what matters under a RTI framework. Reading Psychology, 33(1-2), 162-189. doi:10.1080/02702711.2012.631865

Parodi, G. (2007). Reading-writing connections: Discourse oriented research. Reading and Writing, 20(3), 225-250. doi:10.1007/s11145-006-9029-7

Pyle, N., Vasquez, A. C., Lignugaris-Kraft, B., Gillam, S. L., Reutzel, D. R., Olszewski, A., .. Pyle, D. (2017). Effects of expository text structure interventions on comprehension: A meta-analysis. Reading Research Quarterly, 52(4), 469-501. doi:10.1002/rrq.179

Pytash, K. E., \& Morgan, D. N. (2014). Using mentor texts to teach writing in science and social studies. The Reading Teacher, 68(2), 93-102. doi:10.1002/trtr.1276

Rasch, G. (1960/1980). Probabilistic models for some intelligence and attainment tests. Chicago, IL: Mesa Press.

Reutzel, D. R., Jones, C. D., Clark, S. K., \& Kumar, T. (2016). The Informational Text Structure Survey (ITS2): An exploration of primary grade teachers' sensitivity to text structure in young children's informational texts. The Journal of Educational Research, 109(1), 81-98. doi:10.1080/ 00220671.2014 .918927

Roehling, J. V., Hebert, M., Ron Nelson, J., \& Bohaty, J. J. (2017). Text structure strategies for improving expository reading comprehension. The Reading Teacher, 71(1), 71-82. doi:10.1002/ trtr.1590

Sáenz, L. M., \& Fuchs, L. S. (2002). Examining the reading difficulty of secondary students with learning disabilities: Expository versus narrative text. Remedial and Special Education, 23(1), 31-41. doi:10.1177/074193250202300105

Shanahan, T. (2014). How and how not to prepare students for the new tests. The Reading Teacher, 68(3), 184-188. doi:10.1002/trtr.1315

Tavares, G., Fajardo, I., Avila, V., \& Salmeron, L. (2015). Who do you refer to? How young students with mild intellectual disability confront anaphoric ambiguities in texts and sentences. Research in Developmental Disabilities, 38(108), 108-124. doi:10.1016/j.ridd.2014.12.014

Vuattoux, D., Japel, C., Dion, E., \& Dupéré, V. (2014). Targeting the specific vocabulary needs of at-risk preschoolers: A randomized study of the effectiveness of an educator-implemented intervention. Prevention Science, 15(2), 156-164. doi:10.1007/s11121-013-0379-5

Wei, R. C., Darling-Hammond, L., Andree, A., Richardson, N., \& Orphanos, S. (2009). Professional learning in the learning profession: A status report on teacher development in the US and Abroad. Technical Report. National Staff Development Council.

White, S. (2012). Mining the text: 34 text features that can ease or obstruct text comprehension and use. Literacy Research and Instruction, 51(2), 143-164. doi:10.1080/ 19388071.2011 .553023 
Williams, J. P. (2005). Instruction in reading comprehension for primary-grade students: A focus on text structure. The Journal of Special Education, 29(1), 6-18. doi:10.1177/ 00224669050390010201

Williams, J. P., \& Pao, L. S. (2013). Developing a new intervention to teach text structure at the elementary level. In H. L. Swanson, K. R. Harris, \& S. Graham (Eds.), Handbook of learning disabilities (2nd ed., pp. 361-374). New York, NY: Guilford Press.

Williams, J. P., Pollini, S., Nubla-Kung, A. M., Snyder, A. E., Garcia, A., Ordynans, J. G., \& Atkins, J. G. (2014). An intervention to improve comprehension of cause/effect through expository text structure instruction. Journal of Educational Psychology, 106(1), 1-17. doi:10.1037/ a0033215

\section{Appendix A. Example of step 1 activity}

\section{Sorting (translated)}

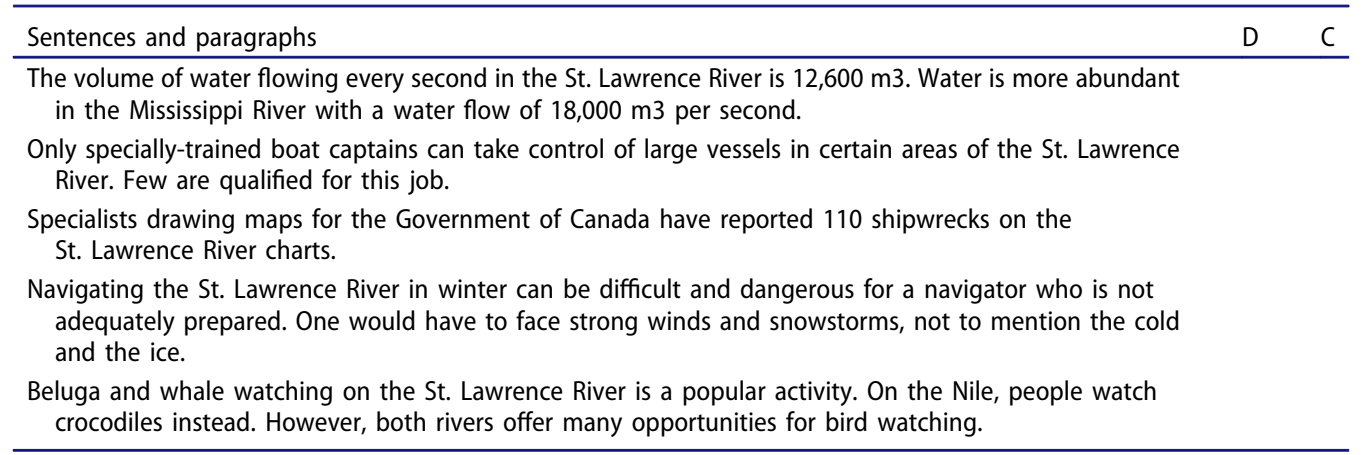

Read the sentences and paragraphs and identify whether they describe (D) or compare (C). Then, highlight the clues that allowed you to classify the sentences or paragraphs.

\section{Example of step 2 activity}

\section{Writing a short comparative text (translated)}

Based on the information provided in the next two paragraphs, write a text with a comparative structure. The steps below indicate the procedure to follow.

1 - Read the two paragraphs.

2 - Identify similar ideas in both paragraphs.

3 - Identify ideas of the same nature by using, for example, highlighters of different colors.

4 - Write your text using appropriate signal words to clarify the links between ideas. If necessary, reformulate ideas or replace words to avoid unnecessary repetition.

5 - Give a title to your text and, if applicable, a subheading to each of your paragraphs. 


\section{The flora and fauna of the St. Lawrence River}

In Canada, the St. Lawrence River flows through boreal forest, mixed forest, and taiga. The beluga is the main mammal observed in this river, but other whales are also found there. During migration season, thousands of white geese stop on the banks of the river for food.

\section{The flora and fauna of the Nile}

In Egypt, the Nile crosses desert, fertile plains, and swamps. The Nile crocodile swims in the river or crawls on its banks. This reptile shares territory with several animal species, including the monitor lizard. Throughout the year, birds such as the cattle egret and the kingfisher can be observed patiently waiting for the fish of the river to feed.

\section{Appendix B. Text and questions sample (translated)}

$(\ldots)$

\section{Tornadoes}

Some tornadoes are made of rather light winds. They cause little damage. Medium-intensity tornadoes can cause significant damage and are more dangerous. Other tornadoes are even faster and more intense. The most powerful tornadoes destroy everything in their path with winds of incredible strength.

\section{Tornado Hunters}

There is a large community of tornado enthusiasts that hunt for these phenomena. Some even spend hours analyzing weather charts. They are ready to travel great distances in order to put themselves at the heart of a tornado. For most of them, it is not a profession but a true passion. They take on nature's challenge, measuring the wind with special equipment and taking pictures. Being a tornado hunter is an extremely dangerous hobby, but true enthusiasts live for the adrenaline. (...)

1 - What is the main idea of the (first) paragraph? (main idea item sample)

Example of a correct answer: Tornadoes differ in strength and in the damage they cause.

Example of an incorrect answer: Some tornadoes are made of rather light wind.

\section{2- The underlined word "they" is a substitution word. What does it replace in this text?}

Correct answers: Tornado hunters/tornado enthusiasts

Examples of an incorrect answer: the tornadoes, the charts 